\title{
Equatorial electrojet in the south Atlantic anomaly region
}

\author{
R G Rastogi ${ }^{1}$, H Chandra ${ }^{1, *}, \mathrm{~N}$ B Trivedi ${ }^{2}$ and V Doumbia ${ }^{3}$ \\ ${ }^{1}$ Physical Research Laboratory, Ahmedabad 380 009, India. \\ ${ }^{2}$ INPE, CP 515, Sao Jose dos Campos, SP, Brazil \\ ${ }^{3}$ Universite de Cocody, Abidjan, Ivory Coast. \\ *e-mail: hchandra@prl.res.in
}

Features of the equatorial electrojet are studied at Sao Luiz $\left(2.6^{\circ} \mathrm{S}, 44.2^{\circ} \mathrm{W}\right.$, inclination $\left.-0.25^{\circ}\right)$ in eastern Brazil and Sikasso $\left(11.3^{\circ} \mathrm{N}, 5.7^{\circ} \mathrm{W}\right.$, inclination 0.1 $\left.{ }^{\circ}\right)$ in the western African sector. The stations are situated on either side of the lowest magnetic field intensity in the region of rapid changes in the declination. The daily variations of $\Delta X$ at the two stations are almost similar with the peak around noon with maximum values during equinoxes and minimum values during J-solstices. Daily variations of $\Delta Y$ differ with the maximum deviation of about $-35 \mathrm{nT}$ around noon at Sao Luiz and much smaller value of about $-10 \mathrm{nT}$ around $14 \mathrm{~h} \mathrm{LT}$ for Sikasso. The direction of the $H$ vector varies from $15^{\circ} \mathrm{W}$ of north at $08 \mathrm{~h}$ to more than $30^{\circ} \mathrm{W}$ of north at $17 \mathrm{~h}$ for Sao Luiz and from $14^{\circ} \mathrm{E}$ of north to $25^{\circ} \mathrm{W}$ of north at $18 \mathrm{~h}$ for Sikasso. The plot of the deviations in $\Delta X$ and $\Delta Y$ at different hours for the two stations shows the points along narrow ellipses with major axis aligned along $22^{\circ} \mathrm{W}$ of north for Sao Luiz and along $3^{\circ} \mathrm{W}$ of north for Sikasso as compared to declination of $20^{\circ} \mathrm{W}$ for Sao Luiz and $6^{\circ} \mathrm{W}$ for Sikasso. The deviations in $\Delta X$ at the two stations are fairly well correlated.

\section{Introduction}

The abnormally large solar daily range of the horizontal component of the geomagnetic field, $\mathrm{H}$, at Huancayo and other equatorial stations was explained by Chapman (1951) as due to a thin sheet of enhanced electric current in the E-region of ionosphere. This intense daytime eastward current within $\pm 3^{\circ}$ dip latitude was named as 'equatorial electrojet' (EEJ). Enhanced current was later explained as an abnormally large electrical conductivity (Hirono 1952; Baker and Martyn 1953). The eastward electric field and the northward magnetic field cause a vertical Hall current in the dynamo region over the dip equator. This is inhibited because of the non-conducting atmosphere below and above the region at 90 and $140 \mathrm{~km}$. Thus vertical polarization field is set up, which significantly enhances the conductivity along the east-west. Polarization field is not sustained beyond $3^{\circ}$ dip latitude as the electrons/ions can move vertically along the inclined magnetic field lines.

Equatorial electrojet has been extensively studied from ground, rocket and satellite based magnetometers, spaced receiver drift, VHF backscatter radar and theoretical studies (Reviews by Forbes and Lindzen 1976; Forbes 1981; Rastogi 1989; Reddy 1989). Features of EEJ have been described for longitude regions of $75^{\circ} \mathrm{W}$ (Forbush and Casaverde 1961), $15^{\circ}-19^{\circ} \mathrm{E}$ (Fambitakoye and Mayaud 1976a, $1976 \mathrm{~b}), 7^{\circ} \mathrm{E}$ (Arora et al 1993; Rastogi 1999) and $5^{\circ} \mathrm{W}$ (Doumouya et al 1998).

A chain of 3-axis digital fluxgate magnetometers at a number of equatorial stations around the world is maintained by Prof. K Yumuto of Kyushu

Keywords. Equatorial electrojet; Brazilian anomaly in equatorial electrojet; asymmetries in equatorial electrojet. 
University, Japan. Rastogi et al (2008) described the features of EEJ along $60^{\circ} \mathrm{W}$ longitude sector using the data from six observatories in central Brazil. Rastogi and Trivedi (2009) and Rastogi et al (2010) described the features of equatorial electrojet in the east Brazilian sector.

It is to be noted that the deviation of the $\mathrm{H}$ field from the geographic north along the dip equator is largest in this sector. We have examined the equatorial electrojet at Sao Luiz $\left(2.6^{\circ} \mathrm{S}, 44.2^{\circ} \mathrm{W}\right.$, inclination $0.25^{\circ} \mathrm{S}$, declination $20.3^{\circ} \mathrm{W}$ ) in eastern Brazil and at Sikasso $\left(11.3^{\circ} \mathrm{N}, 5.7^{\circ} \mathrm{W}\right.$, inclination $0.1^{\circ} \mathrm{N}$, declination $6.4^{\circ} \mathrm{W}$ ) in the western African sector. The geographic coordinates and geomagnetic parameters of the two stations are listed in table 1 . Both the stations are close to the dip equator but declination changes rapidly in the region. Figure 1 shows the map of the location of the two stations. The contours of the total magnetic field intensity $(F)$ and the $Y$ component of the geomagnetic field are also shown in the figure. The stations are situated on both sides of the anomaly. Sao Luiz is located close to the low of $Y(-9368 \mathrm{nT})$ and

Table 1. Geographic and geomagnetic parameters of stations: March 1993.

\begin{tabular}{lrr}
\hline Station code & \multicolumn{1}{c}{ SIK } & SLZ \\
\hline Geog. lat. deg. & 11.3 & -2.60 \\
Geog. long. deg. & -5.7 & -44.20 \\
Declination deg. & -6.4 & -20.34 \\
Inclination deg. & 0.1 & -0.25 \\
X nT & 32200 & 25114 \\
Y nT & -3595 & -9368 \\
Z nT & 80 & -118 \\
H nT & 32400 & 26783 \\
F nT & 32400 & 26783 \\
\hline
\end{tabular}

Sikasso is located little away on other side of the low with $Y$ value of around $-3595 \mathrm{nT}$. In terms of the total intensity, SLZ is located little north of the lowest magnetic field intensity called south Atlantic minimum field anomaly region with total intensity of $26783 \mathrm{nT}$ while SIK is northeast of the low with total intensity of $32,400 \mathrm{nT}$.

\section{Data and analysis}

The geomagnetic field measurements by the 3 -axis fluxgate magnetometers were the component pointing to magnetic north $\left(B_{H}\right)$, magnetic east $\left(B_{Y}\right)$ and vertically downward $(Z)$. The deviations at each hour from the midnight value $(00 \mathrm{~h}$ local time; $45^{\circ} \mathrm{WMT}$ ) have been converted into the geographic northward $(X)$ and geographic eastward $(Y)$ components using the relations described by Rastogi et al (2008).

$$
\begin{aligned}
& \Delta X=\Delta B_{H} \cos (D)+\Delta B_{Y} \sin (D), \\
& \Delta Y=\Delta B_{H} \sin (D)+\Delta B_{Y} \cos (D),
\end{aligned}
$$

where $D$ is the declination.

The analyses used all available data for individual stations for the period January 1993-December 1994. The data were carefully screened and compared with quick look maps available at the website of Kyushu University. Only the days with complete 24 hourly values were used. To have a good statistics of data, only the days with Ap value of less than 20 were selected.

Rastogi et al (2010) made quantitative estimate of the standard error in mean $\sigma / \sqrt{n}$ and of the standard deviation $(\sigma)$ of $\Delta X, \Delta Y$ and $\Delta Z$ at each hour for the month of April 1993 for SLZ. The standard error in mean in $\Delta X$ varied from around $8 \mathrm{nT}$

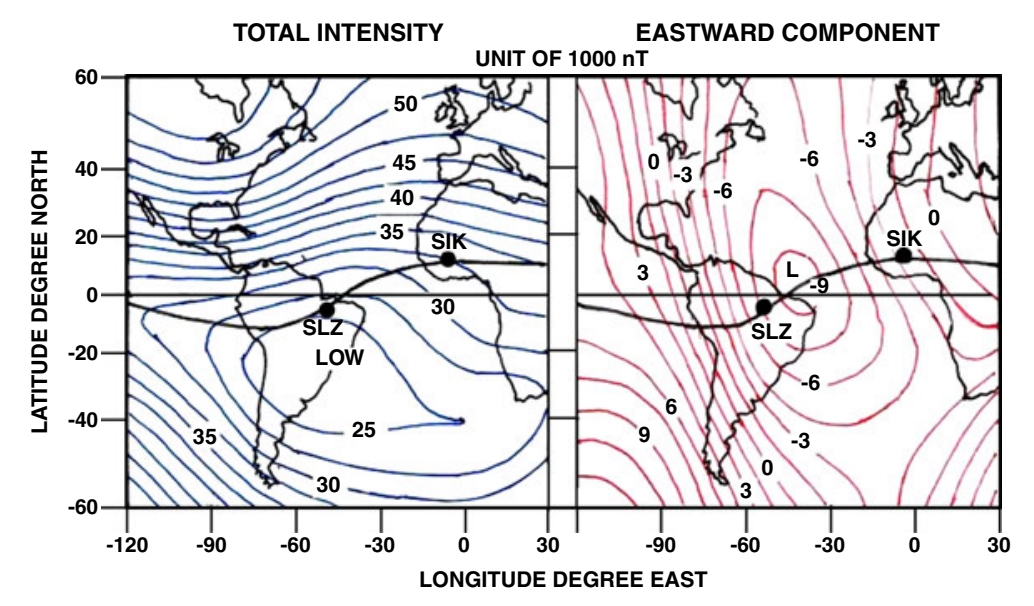

Figure 1. Map showing the location of SLZ and SIK. Contour plots of the total intensity and the eastward component of the geomagnetic field, $Y$, are also shown in the map. 
at noon to $5 \mathrm{nT}$ in the evening-midnight hours. The value of the standard error in mean in $\Delta X$ was least in the midnight-morning hours (1-2 nT). The standard deviation was $40 \mathrm{nT}$ around noon and remained fairly high in the evening-midnight hours with values around $30 \mathrm{nT}$. The standard error in mean in $\Delta Y$ was maximum around noon with a value of about $5 \mathrm{nT}$. The standard deviation was also maximum around noon with a value of $23 \mathrm{nT}$ and decreased to $7-8 \mathrm{nT}$ in the eveningmidnight hours. The high values of the standard deviations at noon are partly because of the dayto-day variability in the electrojet. Based on the mean values and standard errors in mean of $\Delta X$ and $\Delta Y$ at SLZ, the errors in the direction of $H$ vector were computed. Error was very small (about a degree) between 09 and $15 \mathrm{~h}$. The error is very high between sunset and sunrise hours due to low values of the deviations in $\Delta X$ and $\Delta Y$.

\section{Results}

The yearly mean daily variations of $\Delta X$ and $\Delta Y$ at SIK and SLZ for the years 1993-1994 are shown in figure 2(a). The error in mean is not plotted in the figure as it is very small due to the database of 2 years with values ranging from less than $1 \mathrm{nT}$ (midnight to morning) to $2 \mathrm{nT}$ (near noon) for $\Delta X$ and from less than an $\mathrm{nT}$ to $1 \mathrm{nT}$ for $\Delta Y$. The daily variations of $\Delta X$ at the two stations are almost similar with the peak value of $93 \mathrm{nT}$ at SIK little higher than $87 \mathrm{nT}$ at SLZ. This is consistent considering the declination angles at the two locations. The $\Delta X$ values at SIK are expected to be about $5 \%$ higher than at SLZ. The values of $\Delta H$ obtained from $\Delta X$ and $\Delta Y$ at the peak are $93 \mathrm{nT}$ for both the stations. The peak occurs almost around noon (local time) at both the stations. The daily variations of $\Delta Y$, however differ significantly

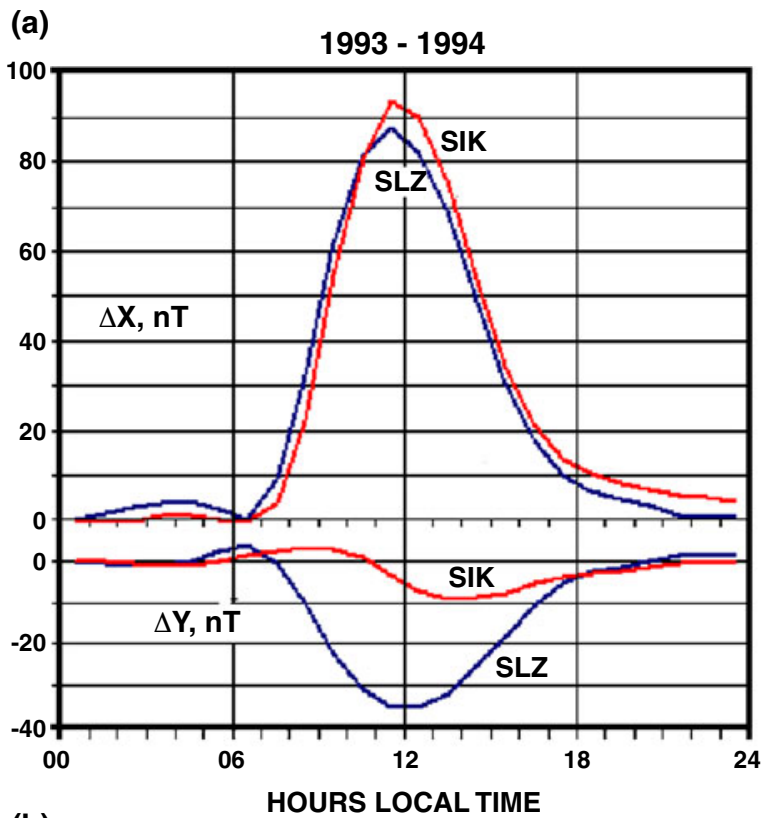

(b)

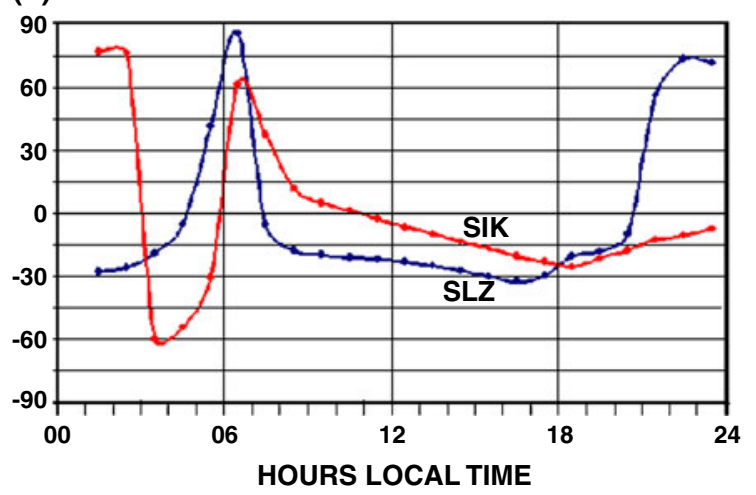

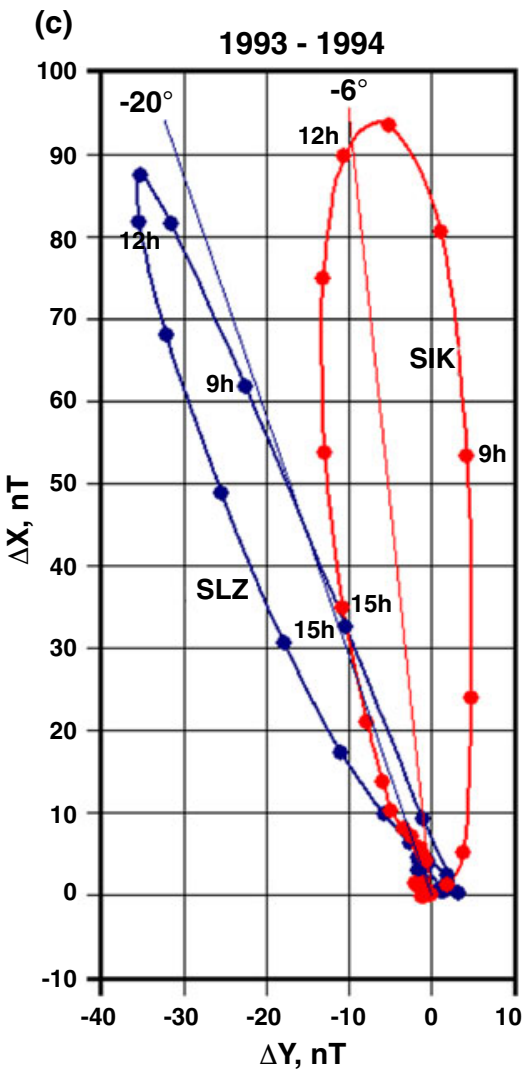

Figure 2. (a) Annual average daily variations of the northward component $\Delta X$ and eastward component $\Delta Y$ of the geomagnetic field at SIK and SLZ for the year 1993-1994. (b) Annual average daily variations of the angle $\theta$, the direction of $H$ vector, perpendicular to the horizontal current at SIK and SLZ for the year 1993-1994. (c) Plots of the annual average hourly values of $\Delta X$ plotted against $\Delta Y$ at SIK and SLZ for the year 1993-1994. 
at the two stations. The maximum deviation of $\Delta Y$ occurs around noon at SLZ with a value of about $-35 \mathrm{nT}$. The deviations are much smaller for SIK with maximum value of about $-10 \mathrm{nT}$ around $14 \mathrm{~h} \mathrm{LT}$. The ranges of $\Delta Y$ at the two locations are again consistent with the declination angles at the two locations ( $\Delta Y$ at SLZ about 3 times that of $\Delta Y$ at SIK). However, the positive deviation in the forenoon and the negative deviation in the afternoon are distinct features at SIK.

The daily variations of the angle $\theta(\arctan \Delta Y)$ $\Delta X$ ), the direction of the $H$ vector (perpendicular to the direction of the current vector) for the two stations are shown in figure 2(b). The $H$ vector for SLZ is aligned around $15^{\circ} \mathrm{W}$ of north at $08 \mathrm{~h}$ in the morning and increases slowly to more than $30^{\circ} \mathrm{W}$ of north around $17 \mathrm{~h}$. Its value is around $30^{\circ}-75^{\circ} \mathrm{E}$ of north in the morning (05-07 h) and late evening hours $(21-00 \mathrm{~h})$. For SIK, it is about $14^{\circ} \mathrm{E}$ of north at $08 \mathrm{~h}$ and changes slowly to about $25^{\circ} \mathrm{W}$ of north at $18 \mathrm{~h}$. The values are up to $60^{\circ} \mathrm{E}$ of north in the morning hours. However, the large values of the angle $\theta$ close to morning or late evening or night hours are due to the fact that the deviations $\Delta X$ and $\Delta Y$ are very small and therefore, the error in estimating current direction is large (Rastogi et al 2010). The error in mean in angle $\theta$ for the data sample of 2 years is $1^{\circ}$ near noon to about $10^{\circ}$ in the night hours. Comparing with the results for stations in east Brazil, the changes in the direction of $H$ vector during daytime at SIK are very large. The direction of the $H$ vector at the two stations is also shown in figure 2(c) where the deviations $\Delta X$ and $\Delta Y$ are plotted at different hours for the two stations. The declination angles at the two stations are also shown in the figure $\left(20^{\circ} \mathrm{W}\right.$ of north for SLZ and $6^{\circ} \mathrm{W}$ of north for SIK). The points lie along an ellipse with major axis aligned along $22^{\circ} \mathrm{W}$ of north for SLZ and along $3^{\circ} \mathrm{W}$ of north for SIK. The ellipse is narrower for SLZ than for SIK. Also while for SLZ most of the points show negative values of $\Delta Y$, for SIK the $\Delta Y$ values are positive in the forenoon and negative in the afternoon hours. There is a difference of about $2^{\circ}$ towards west between the direction of $H$ vector and declination angle at SLZ while the difference is $3^{\circ}$ towards east for SIK. Rastogi et al (2010) found difference of $3^{\circ}$ towards west for stations in east Brazil. For stations in central Brazil, however the $H$ vector was aligned along the magnetic north (current vector perpendicular to the magnetic north) (Rastogi et al 2008).

The daily variations of $\Delta X$ and $\Delta Y$ at SLZ and SIK for the three seasons are shown in figure $3(\mathrm{a})$. As expected, the daily variations of $\Delta X$ show maximum around noon with maximum values during

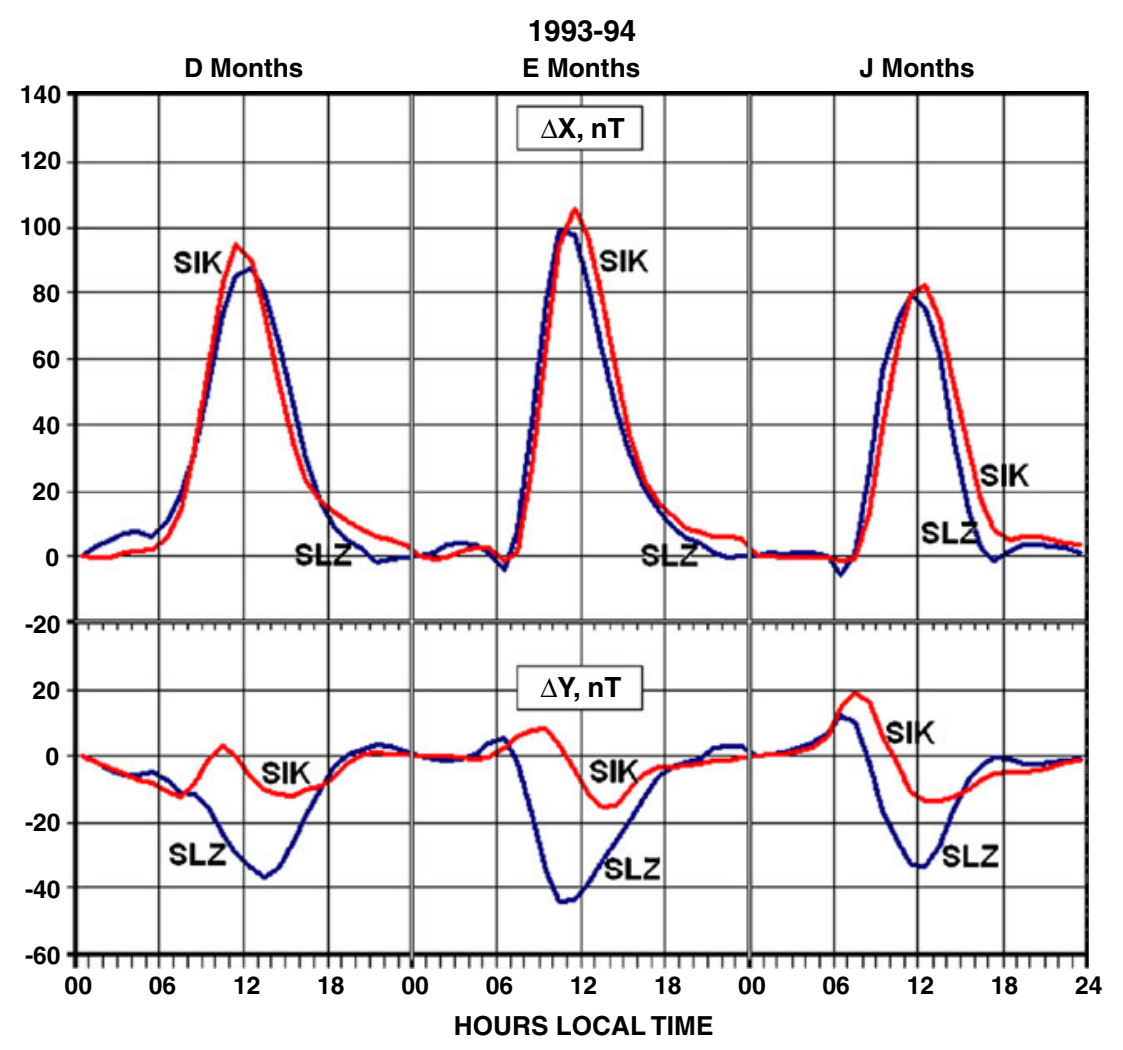

Figure 3(a). Seasonal average daily variations of the northward component $\Delta X$ and eastward component $\Delta Y$ of the geomagnetic field at SIK and SLZ for each of the seasons of 1993-1994. 


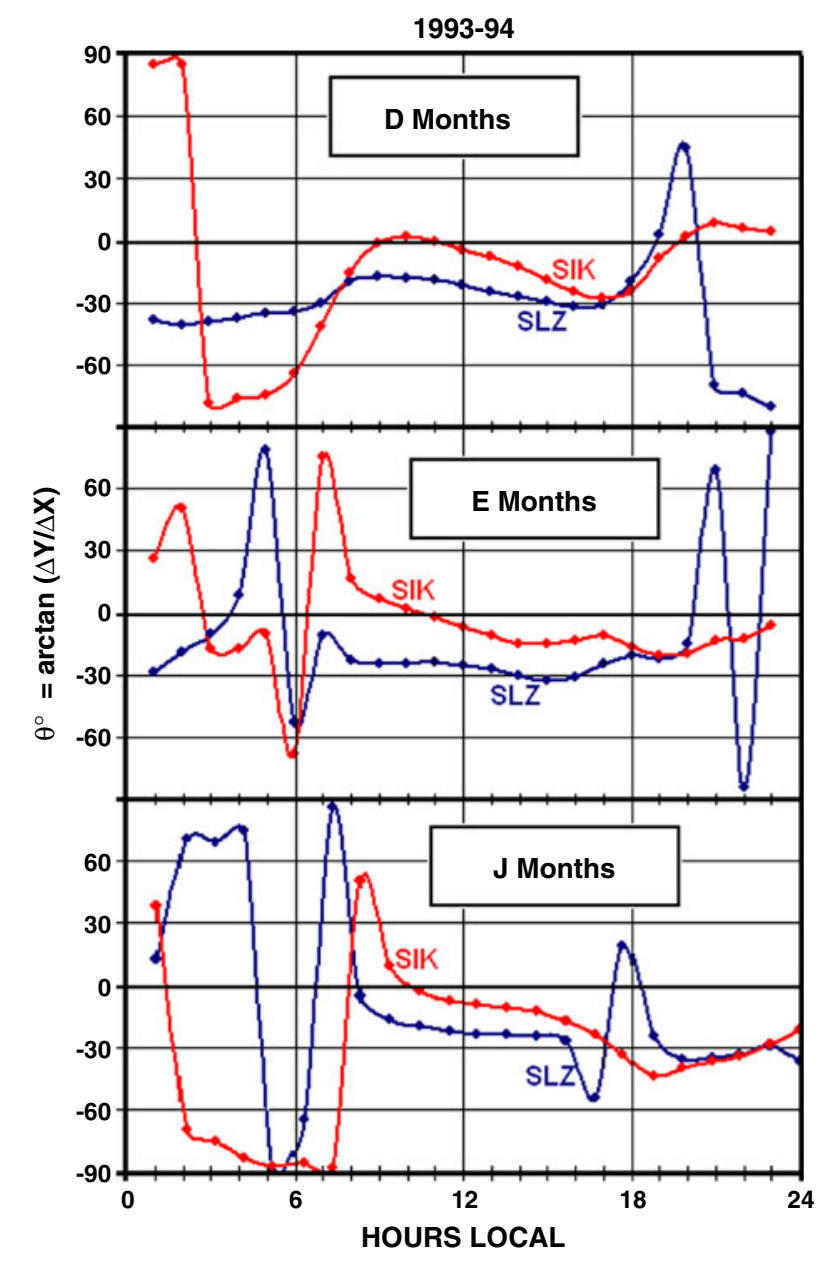

Figure 3(b). Seasonal average daily variations of the angle $\theta$, the direction of $H$ vector at SIK and SLZ for each of the seasons of 1993-1994.

equinoxes and minimum values during J-solstices at both the stations. The daily variations of $\Delta Y$ for SLZ are also as expected with minimum values of -35 to $-45 \mathrm{nT}$ around noon though there is a tendency of it increasing in the post-midnight period with a peak at $06 \mathrm{~h}$ during E-months and Jmonths (5-10 nT). However, the daily variations of $\Delta Y$ for SIK show maximum in the pre-noon hours and minimum in the afternoon hours during each of the seasons. The daily variations of $Y$ at SLZ are negative throughout the day while positive values are evident in the forenoon hours for SIK. Does it signify varying current system at the edges of the anomaly belt of low declination?

The daily variations of the angle $\theta$ during the three seasons are shown in figure 3(b). Large values of the angle during night hours are not significant as discussed earlier (Rastogi et al 2010). For SLZ, the angle $\theta$ during day hours varies from about $18^{\circ} \mathrm{W}$ of north to $30^{\circ} \mathrm{W}$ of north during D-months, from $25^{\circ} \mathrm{W}$ of north to $30^{\circ} \mathrm{W}$ of north during Emonths and from about $15^{\circ} \mathrm{W}$ of north to $25^{\circ} \mathrm{W}$ of north during J-months. For the midday, the values are $20^{\circ} \mathrm{W}$ of north, $27^{\circ} \mathrm{W}$ of north and $25^{\circ} \mathrm{W}$ of north, respectively for the three seasons. The variation of the angle $\theta$ during day hours is comparatively more for SIK with values varying from $0^{\circ}$ to $30^{\circ} \mathrm{W}$ of north during D-months, $15^{\circ} \mathrm{E}$ of north to $15^{\circ} \mathrm{W}$ of north during E-months and $5^{\circ} \mathrm{W}$ of north to $25^{\circ} \mathrm{W}$ of north during J-months. The midday values are $3^{\circ} \mathrm{W}$ of north, $5^{\circ} \mathrm{W}$ of north and $7^{\circ} \mathrm{W}$ of north, respectively for the three seasons.

The vector plots of the $\Delta X$ and $\Delta Y$ for different hours during each season for the two stations are shown in figure $3(\mathrm{c})$. The declination angles at the two locations are also marked in the figure. For SLZ, the points lie along comparatively narrow ellipses pointing to $2-3^{\circ}$ further west of the declination angle. However, the ellipses are little wider for SIK compared to those for SLZ, with orientations almost along the north during D and E-months and about $10^{\circ} \mathrm{W}$ of north during J-months.

The daily variations of the $\Delta X$ and $\Delta Y$ at the two stations for each month are shown in figure 4 . It must be noted that there is no data for SLZ during the months of July and August. Daily variations of $\Delta X$ show clear equinoctial maxima at the two stations with minimum during J-months. Though the variations during daytime are similar for each month, there are minor differences during night hours. In particular, the variations at SLZ show small increase (few $\mathrm{nT}$ ) from midnight to morning hours in some months and a decrease in morning hours to below the night time levels of up to $10 \mathrm{nT}$.

The daily variations of the $\Delta Y$ at SLZ show regular feature of westward component with peak around midday for each month. There are variations during night hours only. The variations at SIK are smaller but show eastward peak before noon and westward peak in the afternoon. Large morning peaks during June to September are significant. For most of the months the value of $\Delta Y$ increases from $06 \mathrm{~h}$ to around $09-10 \mathrm{~h}$ and then decreases very rapidly to minimum shortly after noon. The fluctuations are largest during Jmonths. These features need greater scrutiny with larger set of data.

Few case studies of the daily variations are made on individual days. Figure 5 shows the daily variations of $\Delta X$ and $\Delta Y$ at the two stations on 21 December 1993. The variation of $\Delta X$ at SLZ shows steady rise from midnight to $07 \mathrm{~h}(20 \mathrm{nT})$ and then rapid increase to midday (142 nT). It decreases rapidly till evening and then slow decrease till midnight. $\Delta Y$ decreases steadily from midnight to $07 \mathrm{~h}$ to a value of $-20 \mathrm{nT}$ and then remains to almost same level till $14 \mathrm{~h}$. It increases steadily to midnight. For SIK the variation of $\Delta X$ is similar to that at SLZ but with a lower magnitude (peak of $80 \mathrm{nT}$ at midday). However, $\Delta Y$ variation is 


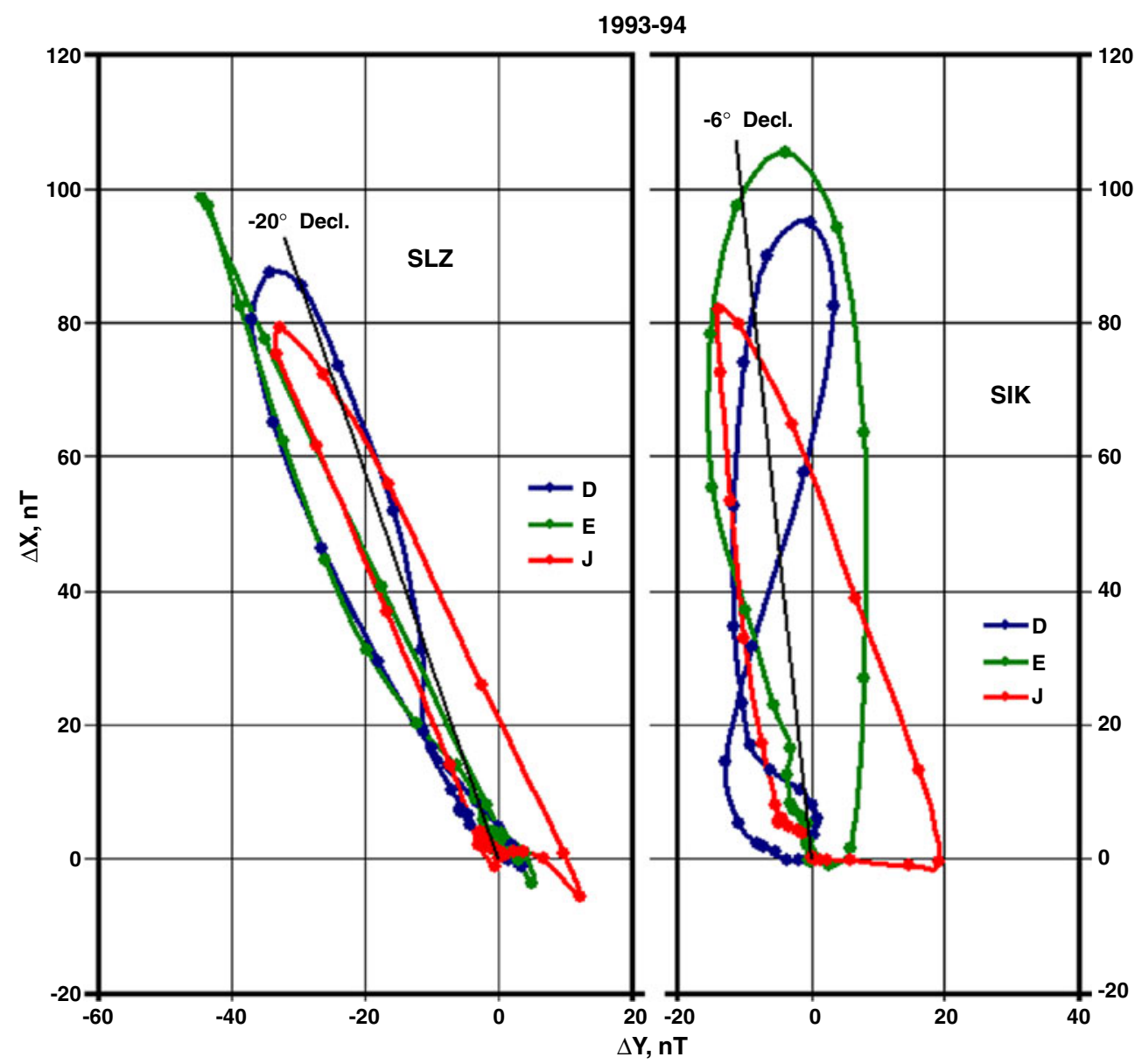

Figure 3(c). Plots of the seasonal average hourly values of $\Delta X$ plotted against $\Delta Y$ at SIK and SLZ for each of the seasons of 1993-1994.

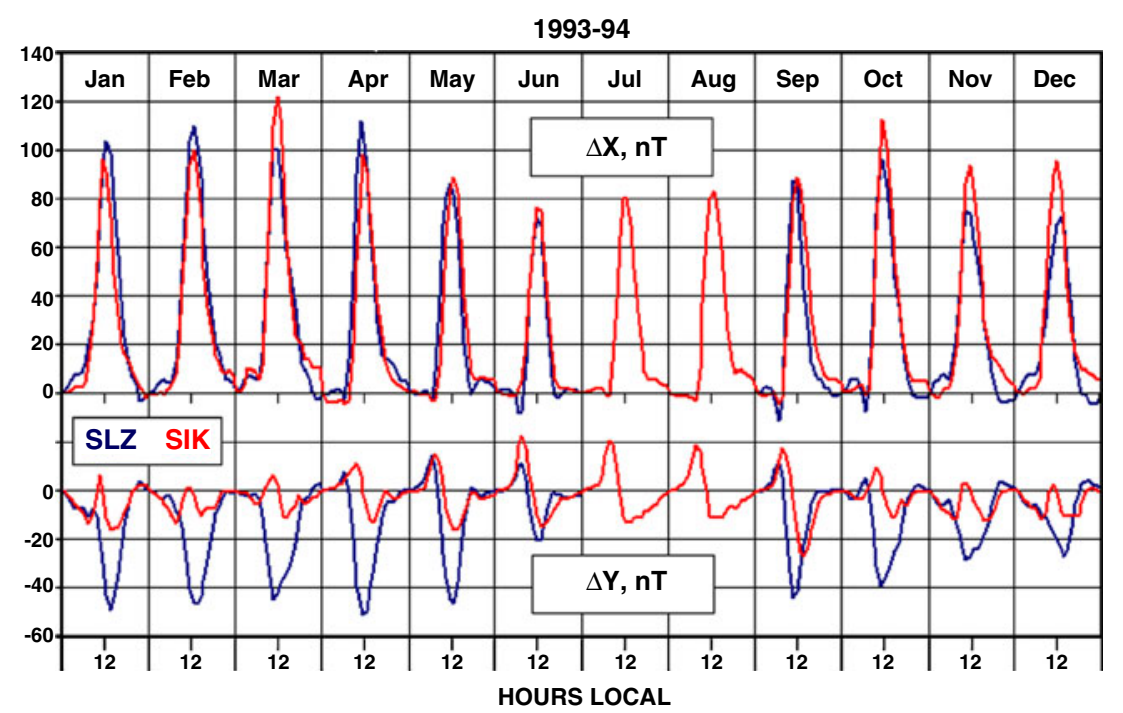

Figure 4. Monthly average daily variations of the northward component $\Delta X$ and eastward component $\Delta Y$ of the geomagnetic field at SIK and SLZ for each months of 1993-1994.

somewhat different. After the slow decrease till $07 \mathrm{~h}$ $(-10 \mathrm{nT})$ it increases to a value of $2 \mathrm{nT}$ at $10 \mathrm{~h}$ and then decreases to almost $-20 \mathrm{nT}$ in the afternoon before recovering to night level.
The daily variations of $\Delta X$ and $\Delta Y$ at SIK on 20 May 1993 and 7 September 1993 are shown in figure 6 . The variations of $\Delta X$ are normal during day time with peak around midday and 


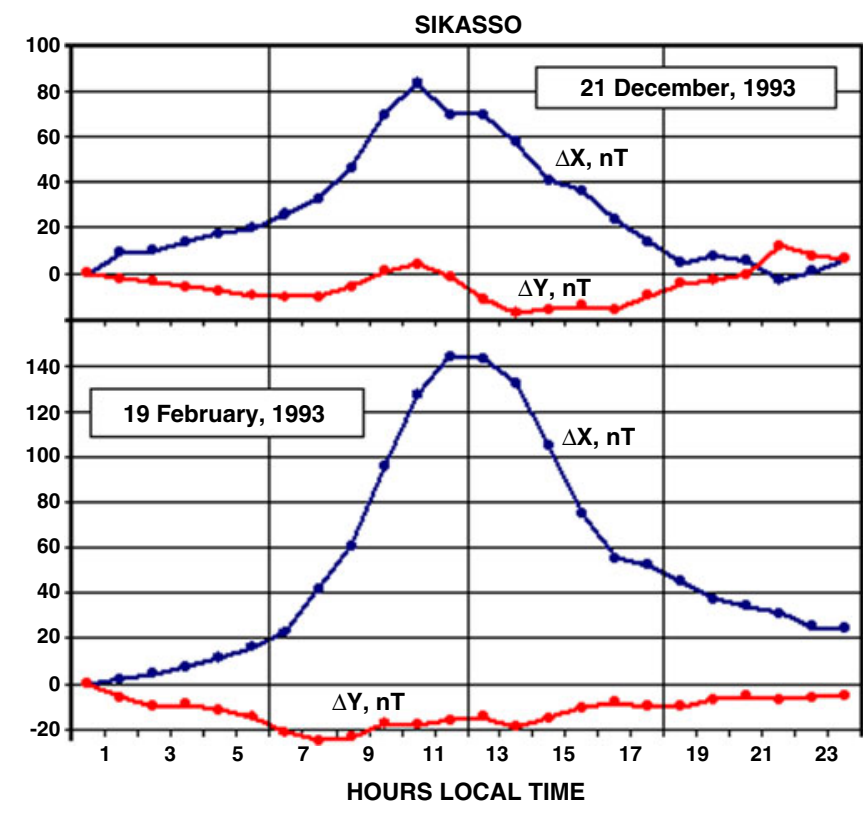

Figure 5. Daily variations of the northward component $\Delta X$ and eastward component $\Delta Y$ of the geomagnetic field at SIK on 21 December 1993 and 19 February 1993.

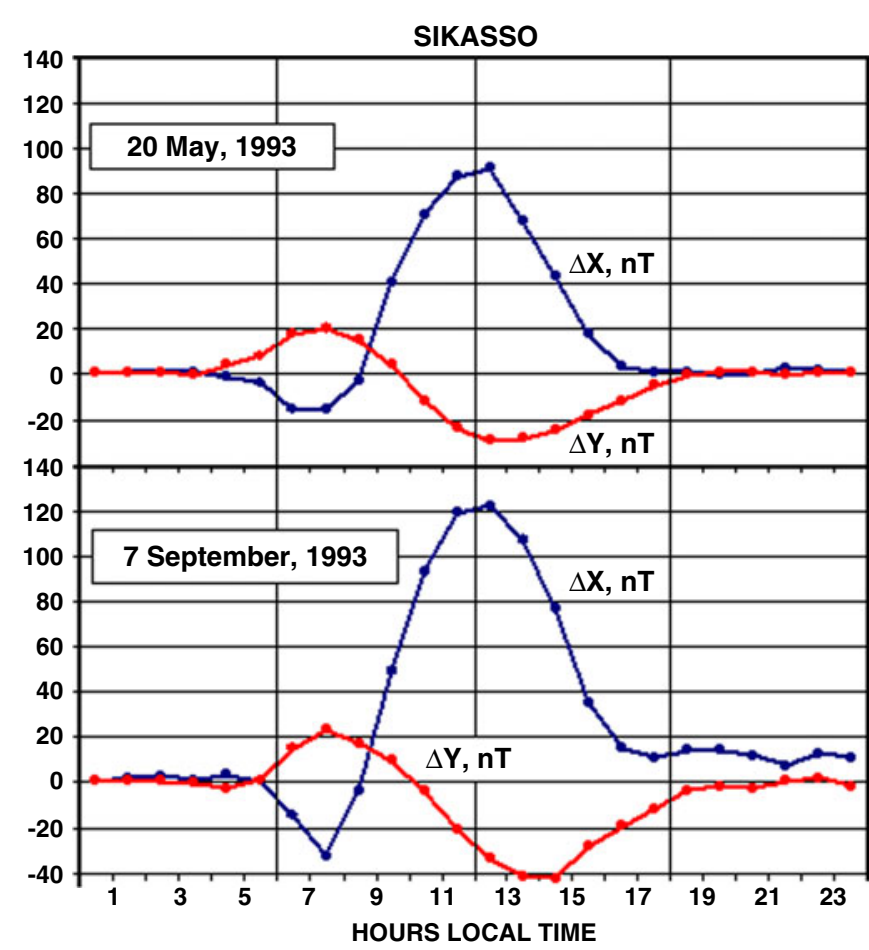

Figure 6. Daily variations of the northward component $\Delta X$ and eastward component $\Delta Y$ of the geomagnetic field at SIK on 20 May 1993 and 7 September 1993.

magnitude of about $90 \mathrm{nT}$ and $120 \mathrm{nT}$, respectively for the two days. However on both days, $\Delta X$ shows decrease of $18 \mathrm{nT}$ and $30 \mathrm{nT}$ from $05 \mathrm{~h}$ to $07 \mathrm{~h}$, respectively on the two days. The variations of $\Delta Y$ show eastward values in the morning with a peak of about $20 \mathrm{nT}$ around $08 \mathrm{~h}$ and then decrease till
$14 \mathrm{~h}$ with westward values of $-30 \mathrm{nT}$ and $-40 \mathrm{nT}$, respectively for the two days. These appear to be morning counter electrojet events. On some days similar events are observed even before sunrise.

Next we computed deviations of hourly means from means of $\Delta X$ and $\Delta Y$ at the two stations from the corresponding value at 0000 LT. Scatter plots of the deviations from mean of $\Delta X$ at the two stations for the three seasons are shown in figure 7 . The correlation coefficients are also marked in the figure. There is fairly good correlation between the deviations in $\Delta X$ at the two stations with correlation coefficients of $0.60,0.55$ and 0.58 , respectively for the three seasons of D-, E- and J-months, respectively. Considering the large separation in longitude between the two stations, correlation is significant. Rastogi et al (2007) reported correlation of 0.65 between the deviations at SLZ and at Ancon separated by about $33^{\circ}$ in longitudes. The separation of the two stations SLZ and SIK is about $38^{\circ}$ in longitudes and the correlation of about 0.6 is

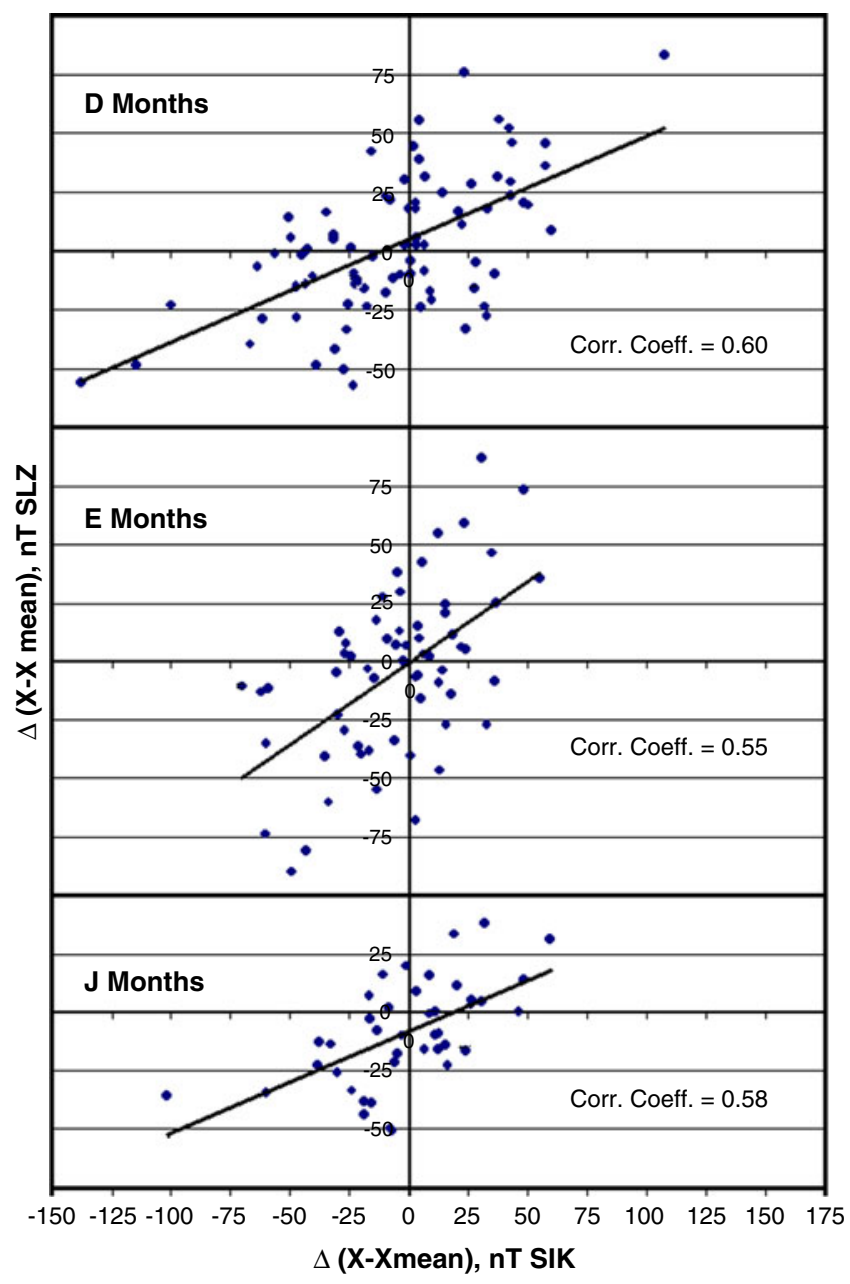

Figure 7. Scatter plots of the deviations (from midnight) in $\Delta X$ at SLZ plotted against the deviations in $\Delta X$ at SIK for the three seasons. Correlation coefficients are also shown. 
consistent with the value reported by Rastogi et al (2007).

However, the correlation between the deviations from mean of $\Delta Y$ at the two stations is absent or poorer as shown for the three seasons in figure 8 . The correlation coefficients are $0.02,-0.24$ and -0.40 , respectively for the three seasons. Therefore the deviations in $\Delta Y$ are uncorrelated during D-months. The negative correlation is poor for E-months and fair during J-months. The negative correlation in $\Delta Y$ is due to the direction of current in opposite direction at the two stations for most of the day hours.

Contour plots of the deviations $\Delta X$ and $\Delta Y$ for SIK are plotted in figure 9 . The contours of $\Delta X$ in red represent northward values (eastward current). Equinoctial maxima around $11 \mathrm{~h}$ are clearly seen. The contours of deviations $\Delta Y$ in red colour represent eastward values. Eastward values are seen during equinoctial and J-months between 05 and $09 \mathrm{~h}$. Maximum westward values are seen in the afternoon hours. Again a loop of large early morning high in July and low in January is clearly

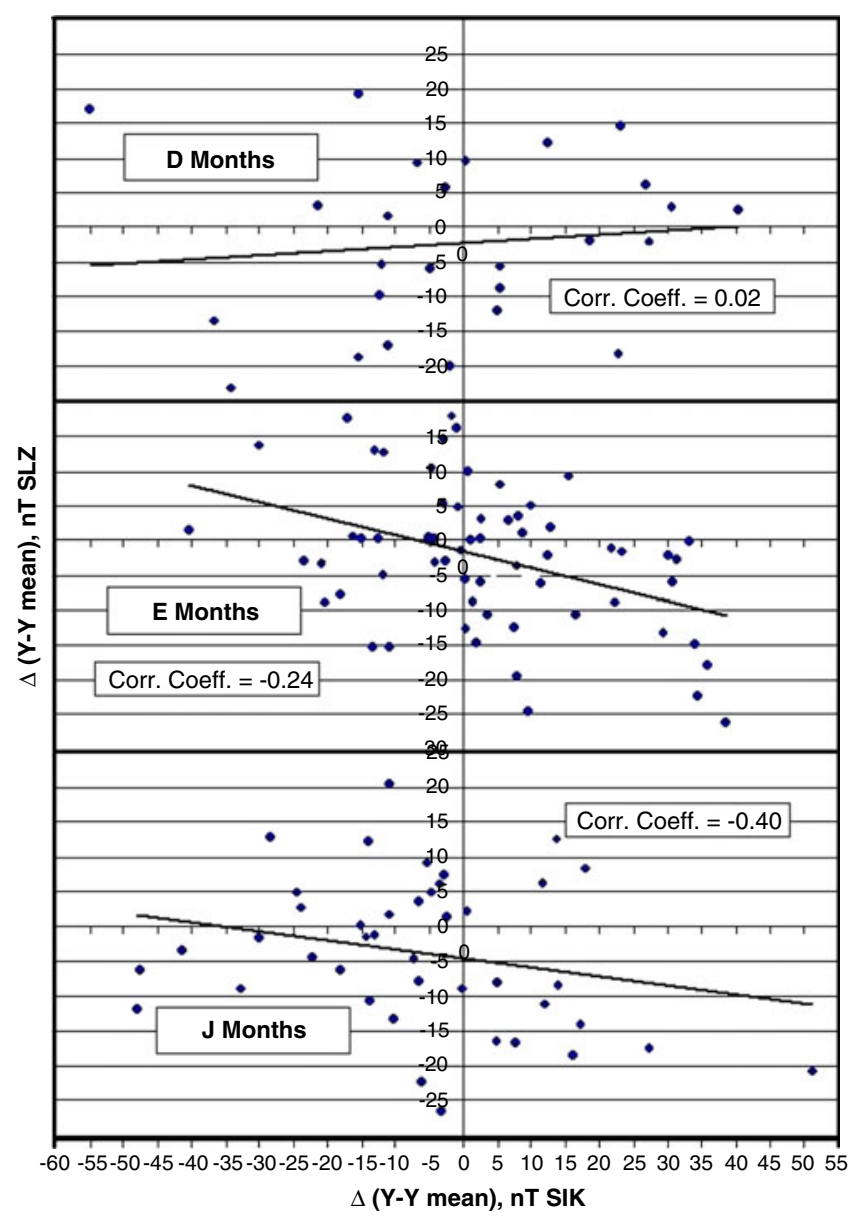

Figure 8. Scatter plots of the deviations (from midnight) in $\Delta Y$ at SLZ plotted against the deviations in $\Delta Y$ at SIK for the three seasons. Correlation coefficients are also shown.

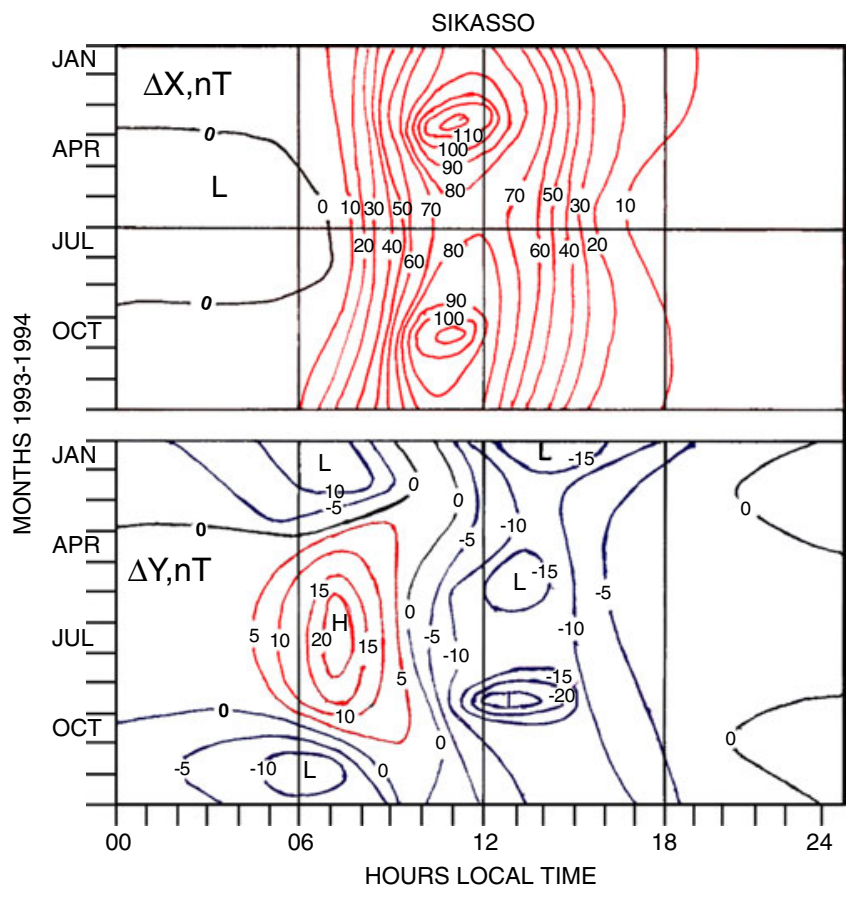

Figure 9. Contour plots of $\Delta X$ and $\Delta Y$ at SIK plotted on a grid of local time versus months.

demonstrated. No such semi-annual variation can be interpreted for the afternoon values of $\Delta Y$.

\section{Discussion}

The annual average variations of $\Delta X$ at SLZ and SIK are almost similar with range at SIK higher by few $\mathrm{nT}$ and consistent with the declination angles at the two locations. The peak $\Delta H$ value obtained from $\Delta X$ and $\Delta Y$ is $93 \mathrm{nT}$ for both the stations. The values of $\Delta X$ at SLZ are not constant after midnight and show an increase from midnight to $05 \mathrm{~h}$. Large differences are seen in the variations of $\Delta Y$, with maximum negative value of $-35 \mathrm{nT}$ around midday at SLZ while at SIK maximum negative value of $-10 \mathrm{nT}$ is seen in the afternoon hours. Though the magnitudes of $\Delta Y$ are consistent with the respective declination angles at the two locations, the variation at SIK is distinct with negative deviation in the forenoon and positive deviation in the afternoon.

The direction of the $H$ vector during daytime varies from $15^{\circ} \mathrm{W}$ of north in the morning to $30^{\circ} \mathrm{W}$ of north in the evening at SLZ. The variation is, however, more at SIK $\left(15^{\circ} \mathrm{E}\right.$ of north to $15^{\circ} \mathrm{W}$ of north). Compared to the declination angle, the $H$ vector during midday is aligned around $2^{\circ}$ towards west at SLZ and around $3^{\circ}$ towards east at SIK.

The seasonal variations of $\Delta X$ are as expected with maximum values during equinoxes and minimum values during $\mathrm{J}$-months at both the stations. The deviations in $\Delta X$ at the two locations are 
fairly well correlated (correlation of 0.6 ). The deviations in $\Delta Y$ are uncorrelated during D-months and negatively correlated during other seasons.

The present analyses suggest that the zonal and meridional components of the ionospheric current are only partially correlated with each other. A significant longitudinal variation exists in the daily variation of these currents.

\section{Conclusion}

Equatorial electrojet at Sao Luiz in eastern Brazil and Sikasso in the western Africa, situated in the region of rapid changes in the declination show similar daily variations of $\Delta X$ with peak around noon with maximum values during equinoxes and minimum values during J-solstices. Daily variations of $\Delta Y$ differ with the maximum deviation of about $-35 \mathrm{nT}$ around noon at Sao Luiz and much smaller value of about $-10 \mathrm{nT}$ around $14 \mathrm{~h} \mathrm{LT}$ for Sikasso. Also the $\Delta Y$ values are positive in the forenoon and negative in the afternoon hours at SIK.

The plot of the deviations in $\Delta X$ and $\Delta Y$ at different hours for the two stations show the points along narrow ellipses with major axis aligned along $22^{\circ} \mathrm{W}$ of north for Sao Luiz and along $3^{\circ} \mathrm{W}$ of north for Sikasso as compared to declination of $20^{\circ} \mathrm{W}$ for Sao Luiz and $6^{\circ} \mathrm{W}$ for Sikasso.

The deviations in $\Delta X$ at the two stations are fairly well correlated. However, the deviations in $\Delta Y$ show poor or weaker negative correlation.

\section{Acknowledgments}

Rastogi and Chandra are thankful to the Director, Physical Research Laboratory, Ahmedabad for the facilities provided. Thanks are also due to the Indian Space Research Organization for the financial support.

\section{References}

Anandarao B G and Raghavarao R 1987 Structural changes in the currents and fields of the equatorial electrojet due to zonal and meridional winds; J. Geophys. Res. 92 2514-2526.

Arora B R, Mahashabde M V and Kalra R 1993 Indian IEEY geomagnetic observational program and some preliminary results; Rev. Bras. Geofis. 11 365-385.

Baker W G and Martyn D F 1953 Electric currents in the ionosphere, 1, the conductivity; Phil. Trans. Roy. Soc. A246 281-294.

Chapman S 1951 The equatorial electrojet as detected from the abnormal electric current distribution above Huancayo, Peru and elsewhere; Arch. Meteorol. Geophys. Bioklimatol. A4 368-390.

Doumouya V, Vassal J, Cohen Y, Fambitakoye O and Menvielle M 1998 Equatorial electrojet at African longitudes:
First results from magnetic measurements; Ann. Geophys. 16 658-676.

Gangepain J, Crochet M and Richmond A D 1977 Comparison of equatorial electrojet models; J. Atmos. Terr. Phys. 39 1119-1124.

Fambitakoye O and Mayaud P N 1976a Equatorial electrojet and regular daily variations of SR-I. A determination of the equatorial electrojet parameters; J. Atmos. Terr. Phys. 38 1-17.

Fambitakoye O and Mayaud P N 1976b Equatorial electrojet and regular daily Variations SR-II. The Centre of the equatorial electrojet; J. Atmos. Terr. Phys. 38 19-26.

Forbes J M 1981 The equatorial electrojet; Rev. Geophys. Space Phys. 19 469-504.

Forbes J M and Lindzen R S 1976 Atmospheric solar tides and their electromagnetic effects, II, The equatorial electrojet; J. Atmos. Terr. Phys. 38 911-920.

Forbush S and Casaverde M 1961 Equatorial electrojet in Peru; Carnegie Institution of Washington, Report No. 620.

Hirono M 1952 A theory of diurnal magnetic variations in equatorial regions and conductivity of the ionospheric $\mathrm{E}$ region; J. Geomagn. Geoelectr. 4 7-21.

Onwumechili C A, Kawasaki K and Akasofu S I 1973 Relationship between the equatorial electrojet and polar magnetic variations; Planet. Space Sci. 21 1-16.

Rastogi R G 1962 Longitudinal variation in the equatorial electrojet; J. Atmos. Terr. Phys. 24 1031-1040.

Rastogi R G 1972 Sudden disappearance of Es-q and the reversal of equatorial electric Fields; Ann. Geophys. 28 $717-728$.

Rastogi R G 1975 On the simultaneous existence of eastward and westward flowing equatorial electrojet currents; Proc. Indian Acad. Sci. 78 80-92.

Rastogi R G 1978 Theory of preliminary negative impulses in SSC in $\mathrm{H}$ at equatorial Stations; Proc. Indian Acad. Sci. 87 57-60.

Rastogi R G 1999 Ionospheric current system in IndoRussian longitude sector; Sci. Cult. 65 269-282.

Rastogi R G 1989 The equatorial electrojet: Magnetic and ionospheric effects; In: Geomagnetism (ed.) Jacobs J, Academic Press 3 461-425.

Rastogi R G 2006 Sq and sfe currents at equatorial stations along the western and eastern African sectors; Earth Planets Space 58 1475-1478.

Rastogi R G and Chandra H 1974 Interplanetary magnetic field and the equatorial Ionosphere; J. Atmos. Terr. Phys. 36 377-379.

Rastogi R G and Chandra H 2002 Equatorial electrojet current flow directions; J. Indian Geophys. Union 6 169-174.

Rastogi R G and Iyer K N 1976 Quiet day variation of geomagnetic H field at low Latitudes; J. Geomagn. Geoelectr. 36 377-379.

Rastogi R G and Patel V L 1975 Effect of interplanetary magnetic field on ionosphere over the magnetic equator; Proc. Indian Acad. Sci. 82 121-141.

Rastogi R G and Trivedi N B 2009 Asymmetries in the equatorial electrojet around N-E Brazil sector; Ann. Geophys. 27 1-17.

Rastogi R G, Chandra H and Misra R K 1971 Effect of magnetic activity on electron drifts in the equatorial electrojet region; Nature 233 13-15.

Rastogi R G, Chandra H, Chakrabarty D K, Kitamura K and Yumuto K 2007 Day-to-day correlation of equatorial electrojet at two stations separated by $2000 \mathrm{~km}$ in Central South America; Ann. Geophys. 25 1-6.

Rastogi R G, Chandra H, James M E, Kitamura K and Yumuto K 2008 Characteristics of equatorial electrojet in Central South America; Earth Planets Space 60 623-632. 
Rastogi R G, Chandra H and Yumuto K 2010 Equatorial electrojet in East Brazil longitudes; J. Earth Syst. Sci. 119 497-505.

Reddy C A 1989 The equatorial electrojet; PAGEOPH 131 485-508.

Richmond A D 1973 Equatorial electrojet, 1, Development of a model including winds and instabilities; J. Atmos. Terr. Phys. 36 1083-1103.

Ronchi C, Sudan R N and Similon P L 1990 Effect of shortscale turbulence on kilometer wavelength irregularities in the equatorial electrojet; J. Geophys. Res. 95 189-200.
Sarabhai V and Nair K N 1971 Morphology of the geomagnetic field variations and a study of the interplanetary magnetic field fluctuations in relation to the daily variations of the geomagnetic field at low latitudes; Cosmic Electrodyn. 2 3-21.

Sugiura M and Cain V C 1966 A model equatorial electrojet; J. Geophys. Res. 71 1869-1877.

Sugiura M and Poros D J 1969 An improved model equatorial electrojet; J. Geophys. Res. 74 4026-4034.

Untiedt J 1967 A model of the equatorial electrojet including meridional currents; J. Geophys. Res. 72 5799-5810. 